\title{
Erratum zu: Historischer Materialismus/Geschichtsmaterialismus
}

Armin Bernhard

\section{Erratum zu: \\ Kapitel „Historischer Materialismus/Geschichtsmaterialismus" in: G. Weiß und J. Zirfas (Hrsg.), Handbuch Bildungs- und Erziehungsphilosophie, https://doi.org/10.1007/978-3-658-19004-0_53}

Am Ende des ersten Abschnitts auf Seite 638 wurde irrtümlich Liebknecht anstelle von Bebel zitiert. Dieser Fehler wurde nun korrigiert. Entsprechend wurde im Literaturverzeichnis „Liebknecht, W. (1913). Die Frau und der Sozialismus. 50. Auf. Stuttgart: Dietz Nachfolge.“ durch „Bebel, a. (1913). Die Frau und der Sozialismus. 50. Auf. Stuttgart: Dietz Nachfolge“" ersetzt. 